veteran's safety behaviours and construct an understanding of how knowledge, attitudes, and beliefs about safety result in health or injury. Veteran's health and safety outcomes will be measured using existing US Veterans Affairs' mental and emotional health analysis tools.

Results Outputs will include modified quality of life and reintegration assessment instruments specific to V2F. This project will also explore if the unique experiences and training of veterans creates a worldview that puts them at particular risk and so establishes V2Fs as a new vulnerable worker population. Results pending and will be available by September, 2016.

Conclusions The study offers a new and emergent means to implementing research into practice by deriving hypotheses from a grounded theory approach and testing them through traditional epidemiological methods. While the V2F movement continues to expand, the unique risks posed to veterans through agriculture should be explored, recognised, and prevented for veterans as an at-risk population.

\section{INJURIES IN RURAL QUEENSLAND, AUSTRALIA: A 17 YEAR EPIDEMIOLOGICAL ANALYSIS}

${ }^{1}$ Watt Kerrianne, ${ }^{2}$ Werner Angela, ${ }^{3}$ Cameron C Menzies, ${ }^{4}$ Franklin Richard. ${ }^{1}$ College of Public Health, Medical and Veterinary Sciences, James Cook University; ${ }^{2}$ Sustainable Minerals Institute, University of Queensland; ${ }^{3}$ Health Institute Queensland, Griffith University; ${ }^{4}$ College of Public Health, Medical and Veterinary Sciences, James Cook University

\subsection{6/injuryprev-2016-042156.366}

Background People living and working in agricultural regions experience higher than average rates of injury. The purpose of this epidemiological study was to examine the incidence and patterns of injury, as well as trends over time, in an agricultural region within SouthWest Queensland, Australia, in order to inform targeted injury prevention strategies. The primary land use is agricultural (sheep and cattle farming).

Methods Data on all patients resident in the study region within SouthWest Queensland who were hospitalised for treatment of an injury (defined as ICD9 codes 800-999, or S00-T98) between $1^{\text {st }}$ January 1995 and $31^{\text {st }}$ December 2011 (17 years), were extracted. ICD codes (including external cause code), age, gender, and length of stay were obtained. Estimated Resident Population data for each year of the study were obtained from the Australian Bureau of Statistics. Cause-specific, age-standardised rates were calculated, as well as age-, gender- and cause-specific rates. Descriptive analyses were completed using SPSS; trends over time were analysed using STATA.

Results There were 60466 hospital admissions during the 17 year data collection period; 7740 of these were injuries $(12.8 \%$ of all hospital admissions; 557 per 10000 per annum). Injury hospitalisation rates increased over the study period $(432.7578$ to 539.5637 per 10000). Hospitalisation due to injury among males decreased over time (645 to 546 per 10000 pa), but increased among females (238 to 445 per 10000 pa). Decreases in injury hospitalisation rates were seen in children ( $0-4 \mathrm{yr}$ olds, and 5-9 yr olds), and adults (45-74 yrs), but rates increased in adolescents (10-14 yrs), young adults (20-44 yrs), and older adults $(75+$ yrs $)$. Falls and poisoning were the leading causes of injury hospitalisation in young children $(28 \%$ and $21 \%$ respectively). Falls and injuries due to transport incidents were the leading causes of injury for 5-9 yr olds (32\% and 24\%). Transport incidents were the leading cause of injury for all other age groups (10-14 yrs: 35\%, 15-19 yrs: 42\%, 20-24 yrs: 32\%, 25-64 yrs:
$28 \%$,) except older adults, where falls were the leading cause of injury hospitalisation (65-74 yrs: 40\%; $75+$ yrs: 62\%).

Conclusion Injury Hospitalisation rates in this agricultural region of QLD are almost double the Australian average. Trends over time in relation to specific injury mechanisms by age group and gender will be presented at the conference. While there is some evidence of injury reduction in this agricultural region during the $17 \mathrm{yr}$ study period, injury prevention strategies specifically targeted toward recreational and work activities in agricultural regions are required to make further reductions. Adolescents, young adults and older adults warrant careful attention.

\section{Child and Adolescent Safety}

\section{Parallel Wed 1.2}

\section{TRANSPORT SAFETY - CHILD MOTOR VEHICLE PASSENGER SAFETY, USING RESEARCH TO BUILD A CAMPAIGN}

Ann Weaver, Alessandra Francoia. Safekids New Zealand

\subsection{6/injuryprev-2016-042156.367}

Background New Zealand's rate of child motor vehicle occupant injury is high by international comparisons. A plethora of research and science has repeatedly stated the safety benefits of keeping children in booster seats until they reach $148 \mathrm{~cm}$ in height. In New Zealand ( prior to 2013) there was no legislation that mandated the use of child restraints beyond the fifth birthday; consequently children were prematurely graduated to adult safety belts and exposed to unnecessary injury risk.

Description of Problem In July 2009, Safekids launched a multipronged, two year campaign to promote regulation change, education and public awareness of the safety benefits of booster seats up to $148 \mathrm{~cm}$ tall. Key activities included:

The creation of a solid base of evidence

The instigation of a national advocacy project to influence government strategy

The delivery of a series of capacity building workshops

The development of creatives to support a nation-wide public awareness campaign.

Results Key findings included:

Utility and value of the Safekids Campaign: 95 percent of esurvey respondents utilised the Campaign to support local action, 83 percent found the key message effective to very effective and 96 percent of respondents found the resources effective to very effective.

Reaching communities: of 100 e-survey respondents, 64 percent primarily worked with indigenous peoples. 360,000 child vehicle passenger safety resources were distributed to areas identified as 'communities at risk'.

Shifting attitudes: 77 percent of e-survey respondents felt that the Campaign had supported the adoption of safer practices. One third of parents interviewed reported that they would prolong their child's use of a booster seat.

Organisational engagement included health services, educators, government and local government, Police and social support services.

Media responsiveness: 34 percent of all recorded media referred to Safekids' NZ child passenger safety information and messaging. 